\title{
«Nunca hazañas de escuderos se escribieron». Porfía e imitación entre Cervantes y Espinel*
}

\author{
NATAlia Palomino TizAdo**
}

\begin{abstract}
Resumen
Este trabajo atiende al ejercicio de imitación y emulación literaria que Vicente Espinel llevó a cabo con el Quijote de Miguel de Cervantes, cuya segunda parte se había publicado tres años antes de que se estamparan las Relaciones de la vida del escudero Marcos de Obregón (1618). Indagamos en la problemática posición que el Marcos de Obregón tiene dentro del corpus picaresco, cuya extraña naturaleza ha hecho que, a día de hoy, siga viviendo en una suerte de limbo literario. La causa, según entendemos y como intentaremos demostrar en estas páginas, se encuentra en la especial relación que la obra de Espinel mantiene con el Quijote cervantino.
\end{abstract}

Palabras clave: Espinel; Cervantes; Relaciones de la vida del escudero Marcos de Obregón; Don Quijote de la Mancha; picaresca; emulación.

Title: «Nunca hazañas de escuderos se escribieron». Rivalry and Imitation between Cervantes and Espinel

\begin{abstract}
This work deals with the exercise of imitation and literary emulation that Vicente Espinel carried out with Don Quijote by Miguel de Cervantes, the second part of which had been published three years before the printing of the Relaciones de la vida del escudero Marcos de Obregón (1618). We investigate the problematic position of Marcos de Obregón within the picaresque corpus, whose strange nature has caused him to continue living in a sort of literary limbo so far. The cause, as we understand and as we will try to demonstrate

* Este trabajo se enmarca en el proyecto de investigación «Vida y escritura II: entre historia y ficción en la Edad Moderna» [PID2019-104069GB-I00] y recoge algunos de los resultados de la investigación desarrollada en el marco de mi tesis doctoral, dirigida por el profesor Luis Gómez Canseco: «Edición crítica y estudio de las Relaciones de la vida del escudero Marcos de Obregón, de Vicente Espinel».

** Universidad de Huelva. natalia.palomino@dfesp.uhu.es / ORCID iD: https://orcid.org/00000002-5172-5920
\end{abstract}


in these pages, lies in the special relationship that Espinel's work maintains with Cervantine Don Quijote.

Keywords: Espinel; Cervantes; Relaciones de la vida del escudero Marcos de Obregón; Don Quixote de la Mancha; Picaresque; Emulation.

\section{Cómo citar este artículo / Citation}

Palomino Tizado, Natalia. 2021. "Nunca hazañas de escuderos se escribieron'. Porfía e imitación entre Cervantes y Espinel». Anales Cervantinos 53: 323-346. https://doi.org/10.3989/anacervantinos.2021.013

En 1618, salían del taller madrileño de Juan de la Cuesta las Relaciones de la vida del escudero Marcos de Obregón, la única obra en prosa que publicó el insigne poeta y músico de Ronda Vicente Espinel. Destacan por su posición problemática dentro del género picaresco y, pese a las notables dudas por parte de la crítica en cuanto a su inclusión -o exclusión- en ese corpus, resulta evidente que la Vida de Marcos de Obregón está inevitablemente ligada a las historias de pícaros y muy en especial al patrón que marcó Mateo Alemán con su Guzmán de Alfarache. Sin embargo, un buen número de indicios sugieren que Espinel hizo una lectura muy atenta del Quijote de Cervantes. El propósito de este trabajo es analizar la conexión que el Marcos de Obregón mantiene con la obra cervantina, y que, a nuestro juicio, podría explicar esa extraña singularidad que lo ha relegado a una suerte de limbo literario. Pero antes de entrar en materia ficcional, conviene detenerse en la relación personal entre ambos autores, que acaso pueda arrojar algo de luz sobre este asunto.

Se ha dado tradicionalmente por hecho que Espinel y Cervantes mantuvieron una estrecha amistad, a partir, claro está, de los elogios que entre ambos se cruzaron ${ }^{1}$. Fue Cervantes, tres años mayor que el rondeño, quien primero dejó, ya en 1585 , constancia de ese trato:

Del famoso Espinel cosas diría que exceden al humano entendimiento, de aquellas ciencias que en su pecho cría el divino de Febo sacro aliento; mas, pues no puede el de la lengua mía decir lo menos de lo más que siento, no digo más, sino que al cielo aspira, ora tome la pluma, ora la lira (Cervantes 2014, 378).

1. Así lo creen varios editores de las Relaciones como Pérez de Guzmán (1881, VII), Gili Gaya (1940, 16) o Rosa Navarro (2008, XV). Gracia (2016, 126 y 408), en su reciente biografía de Cervantes, sigue avalando que Cervantes y Espinel eran buenos amigos. 
Espinel respondió a este elogio incluido en La Galatea desde su poema «La casa de la memoria», estampado como parte de las Diversas rimas en 1591:

No pudo el hado inexorable avaro por más que usó de condición proterva arrojándote al mar sin propio amparo, entre la mora desleal caterva, hazer, Cervantes, que tu ingenio raro del furor inspirado de Minerva, dexase de subir a la alta cumbre, dando altas muestras de divina lumbre (Espinel 2001, 501).

Pura cortesía. Sin embargo, Cervantes quiso insistir, y en 1614 reiteró sus requiebros en el Viaje del Parnaso:

Este, aunque tiene parte de Zoílo, es el grande Espinel, que en la guitarra tiene la prima, y en el raro estilo (Cervantes 2016, 31).

Y, más adelante -acaso irónicamente-, añadía: «Al famoso Vicente Espinel dará V.M. mis encomiendas, como a uno de los más antiguos y verdaderos amigos que yo tengo» (Cervantes 2016, 139).

La respuesta a estos elogios fue el silencio. Parece ser que el maestro de Ronda hizo caso omiso, pese a que no le faltaron oportunidades para corresponder a las gentiles palabras que le dedicó el alcalaíno. Bien es verdad que para entonces la enemistad entre Lope y Cervantes había pasado a mayores y Espinel era un estrecho amigo del Fénix, que lo señaló como su maestro dedicándole siempre muestras de admiración y cariño ${ }^{2}$. No obstante, resulta -cuando menos- extraño que el de Ronda no encontrara hueco en sus Relaciones ni para hacer una mínima mención de Cervantes, aunque fueran cientos los nobles, clérigos y escritores que salen en la obra. Aun cuando Cervantes estuviera ya muerto para cuando salió el Marcos -o acaso por ello_ ${ }^{3}$, cabe preguntarse por qué Espinel evitó dejar memoria póstuma del difunto; y ese silencio de Espinel indica que su amistad con Cervantes, si la hubo, fue meramente circunstancial.

Debieron de conocerse - en el caso de que no hubiera sucedido antes- alrededor de 1584, cuando Espinel se incorporó a la vida literaria de la corte tras su periplo en tierras italianas. Es a partir de 1586, según Haley (1994,

2. En el prólogo de las Relaciones, Espinel recuerda el origen de su amistad con el Fénix, y nos cuenta que «como él se rindió a sujetar sus versos a mi corrección en su mocedad, yo en mi vejez me rendí a pasar por su censura y parecer» (Espinel 2021, 13). Lope, por su parte, elogió en numerosas ocasiones a su maestro. Destaca la dedicatoria de su comedia El caballero de Illescas, donde alude al rondeño como «Apolo de la poesía latina y castellana» o «el insigne gigante de las artes musicales». Otras veces lo menciona como «el gran talento de nuestra edad» o «único poeta latino y castellano de estos tiempos» (Heathcote 1989, 75).

3. Sobre el periodo de composición de las Relaciones, cfr. Espinel (2021, XC-XCII). 
39), cuando pudo consolidarse una suerte de amistad entre ambos, a raíz de la publicación del Cancionero de López Maldonado, en el que tanto Espinel como Cervantes participaron con poemas laudatorios junto a Lope, Liñán de Riaza y Pedro de Padilla. Volvieron a coincidir en 1608, esta vez como miembros de la Congregación de Esclavos del Santísimo Sacramento, establecida como lugar de reunión y frecuentada por las figuras literarias más notables del momento. El cardenal arzobispo de Toledo don Bernardo de Sandoval y Rojas, dedicatario de las Relaciones, tuvo a ambos bajo su amparo. Cuenta Pellicer $(1800,193)$ que el cardenal Sandoval «a cada uno daba una pensión», aunque a Espinel el favor solo le llegó tras la muerte de Cervantes, cuando el cardenal se avino a patrocinar el Marcos de Obregón. No faltaron, pues, ocasiones para facilitar el trato; pero el de Ronda parece que encontró un rival en Cervantes. No sin razón.

A los parcos elogios que intercambiaron se han de añadir las alusiones tácitas que recogen sus obras. Y el primero fue aquí también Cervantes, cuando, en el Quijote de 1615, amo y escudero descubren que se ha publicado un libro que narra sus aventuras. Sancho reconoce que siente cierto temor a que ese misterioso autor, envidioso de sus atributos, haya ultrajado su honra en esas páginas; sin embargo, sus temores se esfuman rápidamente al advertir que quedará por siempre estampado en los libros, y concluye que, sea bueno o malo, tanto le da lo que digan de él mientras su nombre no caiga en el olvido. Don Quijote le responde:

\begin{abstract}
-Eso me parece, Sancho - dijo don Quijote-, a lo que sucedió a un famoso poeta destos tiempos, el cual, habiendo hecho una maliciosa sátira contra todas las damas cortesanas, no puso ni nombró en ella a una dama que se podía dudar si lo era o no; la cual, viendo que no estaba en la lista de las demás, se quejó al poeta diciéndole que qué había visto en ella para no ponerla en el número de las otras, y que alargase la sátira y la pusiese en el ensanche: si no, que mirase para lo que había nacido. Hízolo así el poeta, y púsola cual no digan dueñas, y ella quedó satisfecha, por verse con fama, aunque infame (Cervantes 2015, I, 751-752).
\end{abstract}

La respuesta del caballero andante parece aludir a la «Sátira de las damas de Sevilla» ${ }^{4}$, que el de Ronda compuso durante los años que pasó en la capital hispalense y que, aunque no se publicó, sí circuló manuscrita. Según relata Marcos en las Relaciones, esta fue la etapa más desordenada en la vida de Espinel, y de esas páginas se colige que no se sentía precisamente orgulloso de su comportamiento por esos años. Cervantes, mediante esa finísima intervención de don Quijote, recuerda a los lectores este turbulento periodo vital del rondeño en un momento en que era ya un reputado músico y poeta, rescatando esa célebre sátira que Espinel -significativamente- prefirió obviar en sus Diversas rimas.

4. La «Sátira a las damas de Sevilla» ha sido editada y comentada por Lara Garrido (1993, 411-446). 
Cabe apuntar otra posible referencia al de Ronda en el Quijote de 1605, pues Suárez Figaredo $(2004,134)$ ha señalado que Vicente de la Rosa, soldado fanfarrón, músico y poeta, era un trasunto satírico de Vicente Espinel. Más allá de la pulla nominal ${ }^{5}$, lo cierto es que el retrato de este soldado tiene visibles concomitancias con el rondeño:

En esta sazón vino a nuestro pueblo un Vicente de la Roca, hijo de un pobre labrador del mismo lugar, el cual Vicente venía de las Italias y de otras diversas partes de ser soldado. [...] Sentábase en un poyo que debajo de un gran álamo está en nuestra plaza y allí nos tenía a todos la boca abierta, pendientes de las hazañas que nos iba contando. No había tierra en todo el orbe que no hubiese visto, ni batalla donde no se hubiese hallado; había muerto más moros que tiene Marruecos y Túnez, y entrado en más singulares desafíos, según él decía, que Juan de Urbina, Diego García de Paredes y otros mil que nombraba, y de todos había salido con vitoria, sin que le hubiesen derramado una sola gota de sangre. [...] Añadiósele a estas arrogancias ser un poco músico y tocar una guitarra a lo rasgado, de manera que decían algunos que la hacía hablar; pero no pararon aquí sus gracias, que también la tenía de poeta, y, así, de cada niñería que pasaba en el pueblo componía un romance de legua y media de escritura. Este soldado, pues, que aquí he pintado, este Vicente de la Roca, este bravo, este galán, este músico, este poeta fue visto y mirado muchas veces de Leandra desde una ventana de su casa que tenía la vista a la plaza (Cervantes 2015, I, 632-634).

El maestro Espinel, en efecto, ya había vuelto de Italia -adonde había marchado como soldado- cuando se publicó la primera parte del Quijote. Su fama de arrogante y maledicente era harto conocida, así como su faceta de músico y poeta, cualidades que todos los contemporáneos destacaron en el autor y que coinciden con lo que Cervantes nos cuenta de este personaje ${ }^{6}$. El mismo Suárez Figaredo $(2004,133)$ observa que «aquel Canto a la Patria que compuso Vicente Espinel bien podría ser aquel "romance de legua y media de escritura"» que este poeta soldado componía «de cada niñería que pasaba en el pueblo» ${ }^{7}$. Pese a que no podemos afirmar categóricamente que Cervantes tuviese a Espinel en mente cuando ideó este personaje, lo más probable es que Espinel se sintiera retratado al leer esas páginas. Sea como fuere, tanto esa primera alusión a la «Sátira a las damas de Sevilla», como esta posible caricatura de Espinel en la figura de Vicente de la Rosa, le habrían servido a Cervantes para recordarle al mundo agudísimamente -como era su estilo- que el maestro de Ronda, como los demás, también tuvo episodios en su vida de los que avergonzarse, y que no siempre fue ese prudente e impe-

5. Aunque la variante pueda atribuirse a los cajistas, adviértase que en la princeps «de la Rosa» alterna con «de la Roca».

6. El propio Cervantes, en el elogio de La Galatea, dice que Espinel tiene parte de «Zoílo», aludiendo a su fama de maledicente.

7. La «Canción a su patria» está incluida en las Diversas rimas (Espinel 2001, 459). 
cable hombre al que todos reverenciaban y admiraban cuando se escribía el Quijote.

Hasta aquí el camino que va de Cervantes a Espinel. Pero ¿le respondió el rondeño? Desde luego. Por más que no se registre referencia explícita al Quijote, en el Marcos asistimos a un muy pensado ejercicio de emulación para con Cervantes. La prosa de Espinel se acerca mucho a la escritura cervantina: destaca por su ligereza, libertad y naturalidad, y es menos tortuosa y alambicada que la de Alemán o Quevedo. De ahí que Carrasco $(1972,30)$ subraye que «la obra de Cervantes actuará sobre Espinel como fuerza de atracción, que contrarresta hasta cierto punto la de Alemán, al ofrecer la alternativa de un mundo novelesco de mayor libertad y abertura». Es esta la opinión general de la crítica espineliana, aunque a nuestro juicio el maestro de Ronda fue un paso más allá. Rescatamos aquí la idea que, en 1800, sugirió Pellicer y que resume Pérez de Guzmán (1881, VII):

Pellicer en la Vida de Cervantes ha querido encontrar el origen del Marcos de Obregón en un movimiento de emulación del anciano maestro hacia el genio divino del autor inmortal del Quijote [...]. El diligente biógrafo no ha dado pruebas bastantes de lo que aseveraba, sino meras conjeturas que bien pudieran estrellarse en la noción que tenemos de la amistad y el respeto recíproco que en vida uno y otro se profesaban ${ }^{8}$.

Pellicer, sin embargo, no se equivocaba, y hay pruebas que corroboran su intuición.

\section{CONVERGENCIAS NARRATIVAS}

Las Relaciones se inician con lo que parece ser una insidiosa alusión al Quijote de Cervantes:

No será Marcos de Obregón el primero escudero hablador que ha visto vuestra señoría ilustrísima, ni el primero que con humildad se ha postrado a besar el pie de quien tan bien sabe dar la mano para levantar caídos, mas será el primero escudero que se ha confesado por ignorante... (Espinel 2021, 8).

No es casual que Espinel destaque precisamente esa cualidad de «hablador», quizás la más sobresaliente del escudero cervantino. Además, como ya advirtió Pellicer (1800, 194), Cervantes se refiere a don Bernardo en el prólogo al Quijote de 1615:

8. Cfr. Pellicer $(1800,193)$. 
Viva el gran conde de Lemos, cuya cristiandad y liberalidad, bien conocida, contra todos los golpes de mi corta fortuna me tiene en pie, y vívame la suma caridad del ilustrísimo de Toledo, don Bernardo de Sandoval y Rojas, y siquiera no haya emprentas en el mundo, y siquiera se impriman contra mí más libros que tienen letras las coplas de Mingo Revulgo. Estos dos príncipes, sin que los solicite adulación mía ni otro género de aplauso, por sola su bondad, han tomado a su cargo el hacerme merced y favorecerme, en lo que me tengo por más dichoso y más rico que si la fortuna por camino ordinario me hubiera puesto en su cumbre (Cervantes 2015, I, 677).

Espinel, que, para cuando redactó su dedicatoria, ya había leído estas páginas, vino a reconocer que su escudero no era el primero en presentarse ante el cardenal, pues ya lo había hecho Panza con el segundo Quijote. Una vez más hubo de conformarse con ser segundo, ahora también al ofrecer al magnate un libro de entretenimiento con un escudero como protagonista. Pero la queja sigue unas páginas más adelante, en el prólogo al lector de las Relaciones. Veámoslo:

El intento mío fue ver si acertaría a escribir en prosa algo que aprovechase a mi república, deleitando y enseñando, siguiendo aquel consejo de mi maestro Horacio; porque han salido algunos libros de hombres doctísimos en letras y opinión que se abrazan tanto con sola la doctrina que no dejan lugar donde pueda el ingenio alentarse y recebir gusto; y otros, tan enfrascados en parecerles que deleitan con burlas y cuentos entremesiles que, después de haberlos leído, revuelto, ahechado y aun cernido, son tan fútiles y vanos que no dejan cosa de sustancia ni provecho para el lector, ni de fama y opinión para sus autores. El padre maestro Fonseca escribió divinamente del amor de Dios, $y$, con ser materia tan alta, tiene muchas cosas donde puede el ingenio espaciarse y vagarse con deleite y gusto... (Espinel 2021, 14).

En esta censura de los libros que solo deleitan «con burlas y cuentos entremesiles» -que, según el de Ronda, carecen de profundidad y doctrina- podría cifrarse una alusión al Quijote. Cabría decir que la censura sirve para otros libros de entretenimiento, pero la inmediata alusión al maestro Fonseca remite inequívocamente al prólogo cervantino de 1605 y su mención -irónica- del Tratado del amor de Dios, que fray Cristóbal de Fonseca había estampado en 1592:

Si tratáredes de amores, con dos onzas que sepáis de la lengua toscana, toparéis con León Hebreo que os hincha las medidas. Y si no queréis andaros por tierras estrañas, en vuestra casa tenéis a Fonseca, Del amor de Dios, donde se cifra todo lo que vos y el más ingenioso acertare a desear en tal materia (Cervantes 2015, I, 17).

La referencia a Fonseca une ambos preliminares; pero cabe preguntarse por qué Espinel salió en su defensa trece años después ${ }^{9}$. Y parece que sim-

9. Suárez Figaredo $(2004,136)$. 
plemente quería abrir una nueva línea de combate con un texto que entendió como su contrincante editorial. Al fin y al cabo, Espinel, censor de libros y tertuliano en varios círculos literarios, pudo adivinar, no sin disgusto, la trascendencia que alcanzaría la obra cervantina.

Si pasamos de los paratextos a la ficción, veremos cómo Marcos cruza por un bosquecillo del Carpio con su endemoniado macho y se apea, pues siente la urgencia de «cierta necesidad natural y forzosa» (Espinel 2021, 136). De repente, una culebra asusta al animal y lo hace huir. Lucha Marcos con la sierpe y se detiene a explicarnos la naturaleza de estas alimañas que provocan pavor. Pero, tras su reflexión, observa:

Hasta aquí había estado el ermitaño callando ${ }^{10}$, y aquí pareciole preguntar -como hombre que había estado en soledades y entre ásperas montañas, huyendo el concurso de la gente, viviendo y conversando animales brutosqué era la razón por que estas sabandijas son tan espantables, como son culebras, lagartos, sapos, escuerzos, áspides, víboras y otras semejantes que suelen verse (Espinel 2021, 137).

Si hay algo que caracterice a nuestro escudero es su pasión por contar: contar por sí mismo, contar lo que le contaron los demás, contar lo que otros escucharon... ${ }^{11}$. Contra todo pronóstico, responde a la pregunta en pocas líneas y concluye con un rotundo: $" Y$ esto baste, porque la pérdida de mi macho me da pena y cuidado, y priesa que lo busque» (Espinel 2021, 138).

Esta inusual conducta de Marcos hace que nos planteemos varias cuestiones: ¿por qué ese empecinamiento en encontrar a esa endiablada bestia que solo le daba problemas? ¿Por qué hace que su interlocutor -cuya presencia el lector ya había olvidado- interrumpa el relato justo en el momento en que se narra algo aparentemente insignificante y remarcando, asimismo, que había estado callado hasta entonces? ¿Por qué despacha en apenas unas líneas la pregunta del ermitaño, rematando con ese tajante «Y esto baste», para que no

10. Recordemos que las Relaciones se inician con la imagen de Marcos ejerciendo de ensalmador en Santa Catalina de los Donados, Madrid, desde donde se dispone a escribir su vida. En este momento, se produce una primera analepsis que nos retrotrae a unos años atrás, cuando Marcos empieza a servir al matrimonio Sagredo. Pasa varios descansos como ayo de la soberbia doña Mergelina, esposa del doctor Sagredo, hasta que el matrimonio se marcha a Castilla y Marcos queda desacomodado. Se dispone a volver a Andalucía, pero una gran tormenta lo obliga a refugiarse en la ermita del Santo Ángel de la Guarda, custodiada por un ermitaño que resulta ser un antiguo conocido. Hasta este punto, el discurso de Marcos se dirigía al cardenal Sandoval y a nosotros como lectores. Sin embargo, guarecidos de las inclemencias del tiempo, el ermitaño insta a Marcos a que le cuente su vida, produciéndose aquí una segunda analepsis que nos lleva a la infancia de Marcos en Ronda. A partir de este momento, pues, el relato de la vida de Marcos pasa a un formato dialogístico, y el ermitaño se mantiene como interlocutor del escudero casi hasta el final de la novela. Rallo (2014, XL), con respecto a esta cuestión, ha apuntado que «la conversación con el ermitaño introduce un tiempo-marco que se superpone al tiempo del desarrollo vivencial, dotándolo de elasticidad organizativa. Algo parecido al Coloquio de los perros en el que Cervantes también utiliza la fórmula dialogal para revalidar una historia en sí fantástica, ya que un perro habla». Cfr. Carrasco $(1990,130)$.

11. En palabras de Navarro (2008, XIII), «lo que le gusta a Espinel es contar que alguien cuenta que alguien cuenta...». 
lo despiste de su principal intento, que no es otro que dar con el macho? Este episodio de la obstinada búsqueda del mulo sugiere que Espinel, a través de esta anécdota, alude a la pérdida del rucio de Sancho. Cervantes subsanó este lapsus narrativo incluyendo una explicación en la segunda edición salida también en 1605, donde se señalaba a Ginés de Pasamonte como responsable del hurto ${ }^{12}$. Si los personajes cervantinos encuentran luego a Ginés disfrazado de gitano y a lomos del rucio, Marcos también halla a su macho en manos de unos gitanos, que pretenden venderlo como bestia mansa después de haberlo emborrachado.

Cervantes dejó confusos a los lectores al olvidar resolver el asunto del paradero del rucio; Espinel, sin embargo, se esfuerza en recalcar que no desistirá hasta encontrar a su macho extraviado. Pero lo más sorprendente es que el ermitaño -quien, exceptuando los breves pasajes que anteceden a los descansos al comienzo de cada relación, interviene solo en dos ocasiones, en este episodio y cuando el escudero le cuenta su experiencia en tierras argelinas- se inmiscuya en el discurso de Marcos para hacerlo divagar justo en el momento en que empieza a narrar la obcecada búsqueda del animal ${ }^{13}$. Según entendemos, Espinel se sirve de esta interrupción improcedente para decirnos que, pese a los intentos de distracción por parte de su interlocutor, no permitirá que en su relato queden cabos sueltos; que él, en definitiva, y a diferencia de Cervantes, no desconcertará a los lectores de las Relaciones.

\section{CAUTIVOS, SOLDADOS Y BANDOLEROS}

Aunque el tema del cautiverio era un motivo recurrente en la literatura áurea, la inclusión del episodio argelino en las Relaciones también está en deuda con Cervantes, que ya lo había utilizado en varias obras como El trato de Argel, La gran sultana, Los baños de Argel, las Novelas ejemplares o el Quijote. El problema aquí es la razón por la cual Espinel hace que Marcos sufra personalmente ese cautiverio. Pudiera haber bastado con insertar algún relato o cuentecillo en que se tratara el asunto, como hace, ciertamente, en el descanso 13 de la segunda relación, cuando el renegado deleita a Marcos con la historieta de la cautiva valenciana. Hasta el momento del rapto, las Relaciones siguen una pauta transparentemente autobiográfica para construirse, pero de pronto Marcos se convierte en protagonista de un episodio que jamás

12. Rico (Cervantes 2015, I, 273), en su edición del Quijote, explica al detalle este desliz narrativo que cometió Cervantes con la pérdida del rucio. En el apéndice, asimismo, podemos leer la adición al capítulo XXIII según la edición revisada de 1605, donde se narra la pérdida y recuperación del asno de Sancho (Cervantes 2015, I, 1343).

13. Sevilla (2011, XXXV) advierte que esta interrupción del ermitaño es un sinsentido. Al analizar la naturaleza dialogística de la obra, señala que la figura del ermitaño «legitima la interminable serie de considerandos ascéticos desperdigados a lo largo de la relación, a veces tan plúmbeos y tan sin propósito (en I-XV, v. gr., con motivo de la culebra que sale al paso del macho) -todo sea dichoque solo un destinario así sería capaz de tragarse». 
vivió el de Ronda en carne propia. Aun así, los lectores contemporáneos de Espinel, como los de los siglos posteriores, leyeron la obra como una suerte de memorias noveladas, incluyendo el episodio argelino. Hubo que esperar a los estudios de Haley para saber que nunca puso los pies en Argel ${ }^{14}$. Sin embargo, logró hacer creer a los lectores del libro que él también, como Cervantes, había sido sufrido cautiverio en tierras enemigas ${ }^{15}$.

Acaso Espinel -ante el espejo de la vida heroica de Cervantes, cifrada simbólicamente en su mano izquierda- quiso adornar a su héroe y, de paso, a sí mismo con situaciones que lo pudieran presentar como un hombre de acción ${ }^{16}$. Pero lo cierto es que, incluso en esas situaciones propicias, ya sean batallas, naufragios, raptos, cautiverio o encuentros con bandoleros, el escudero opta siempre por valerse de la razón y la paciencia, para que nadie dude de que Marcos de Obregón es solo un disfraz tras el que se esconde Vicente Espinel. El proceso educativo que el escudero despliega con los hijos del renegado constituye el eje sobre el que se construye el episodio argelino; es más, parece que esta desafortunada aventura funciona como mero telón de fondo donde realzar, más si cabe, su faceta de educador, pues vemos que, aun siendo esclavo del enemigo, se erige como dechado de resiliencia y virtud, evitando siempre cualquier forma de violencia y distanciándose, por ende, del personaje de don Quijote.

En este sentido, se antoja muy revelador el inicio que le da Espinel a las Relaciones. Recordemos que en el descanso 1 de la relación primera, Marcos se encuentra en Santa Catalina de los Donados ejerciendo de ensalmador. Cierto día, mientras pronuncia un ensalmo a oídos de un enfermo, un cortesano que observa la situación dice al pasar: «No puedo sufrir los embelecos de estos embusteros» (Espinel 2021, 25). Sin duda, estas palabras habrían enfurecido al loco manchego, y no es difícil adivinar el grotesco espectáculo que nos habría regalado si hubiese recibido una afrenta semejante. Sin embargo, cuando el compañero de Marcos le pregunta si no ha oído cómo lo han llamado, nuestro escudero responde en estos términos: «Él no habló conmigo - dije yo-y, de lo que a mí no se me dice derechamente, no tengo obligación de sentirme ni hacer caso» (Espinel 2021, 25). E inserta inmediatamente una

14. Aunque Pérez de Guzmán (1881, XIV) sostuvo que este episodio había formado parte de la biografía del rondeño, alegando que «o hay que aceptar como cierto en el Marcos de Obregón este episodio autobiográfico de Espinel o hay que negarlos todos», Haley $(1994,36)$ advierte que «no existe evidencia alguna que lo acredite, pues ni el nombre de Espinel figura en las listas de cristianos redimidos confeccionadas por los religiosos mercedarios, ni el supuesto cautiverio fue mencionado por ninguno de sus contemporáneos y -lo más extraño aún- ni el mismo Espinel, fuera del Marcos, alude a este episodio»».

15. Ya hemos visto que Espinel, en el único elogio que dedica al autor del Quijote en «La casa de la memoria», alude al cautiverio que sufrió el alcalaíno. Parece que esta experiencia vivida por Cervantes impresionó considerablemente al poeta de Ronda.

16. Haley $(1994,181)$ también intuye una posible emulación de Cervantes en el episodio argelino: «Interesante asunto para la especulación es el de saber hasta qué punto tenía Espinel en mente las experiencias de Cervantes, y si albergaba algún deseo subconsciente de emularlas, si bien solo como Marcos de Obregón». Rallo (2014, XVI), aceptando esta propuesta de Haley, añade que «si no es una emulación de vida lo es de literatura». 
digresión sobre la necesidad de ejercer la virtud de la paciencia ante este tipo de agravios. Desde el comienzo, a nuestro parecer, Espinel se propone marcar distancias con el héroe cervantino, corrigiendo, con su ejemplo, el comportamiento que aquel habría empleado ante una situación tan problemática.

No obstante, el escudero de Ronda y el caballero andante parecen ser dos caras de la misma moneda; aunque sus armas no son las mismas, sí lo es su misión: ambos se dedican a «desfacer agravios», socorrer a los necesitados y a luchar, al fin y al cabo, por la libertad ${ }^{17}$. Sin embargo, mientras don Quijote se atiene a su lanza para ser fiel a los libros de caballerías, Marcos de Obregón se vale de la palabra para ayudar al mundo. No le cabía otra a Espinel, siempre delicado de salud, torturado desde joven por la gota e inclinado a la gordura, tal como él mismo se pintó jocosamente en su epístola al marqués de Peñafiel:

Con la gordura tengo un ser de mostro, grande la cara, el cuello corto y ancho, los pechos gruesos, casi con calostro; los brazos cortos, muy orondo el pancho, el ceñidero de hechura de olla, y a do me siento hago allí mi rancho; cada mano parece una centolla, las piernas torpes, el andar de pato, y la carne al tobillo se me arrolla; [...] cualquiera cosa para andar me estorba, redondo el pie, la planta de bayeta, las piernas tiesas y la espalda corva (Espinel 2001, 623).

La imagen es toda una contrafigura de don Quijote y, de hecho, también Marcos, como alter ego de Espinel, se adapta a su particular idiosincrasia; por eso, ante las adversidades, opta siempre por la cautela, el razonamiento y el consejo. Aunque, como al caballero cervantino, a este escudero se le presentan ocasiones para ejercer la fuerza, prefiere no comportarse como un loco, actuar racionalmente y obtener siempre el provecho de la victoria.

Un buen ejemplo de ello es su paso por Italia como soldado. Aun cuando exhiba el atuendo militar e insista varias veces en que esa era su condición, lo cierto es que en ningún momento lo vemos ejercer, por más que alardee de haber participado en el sitio de Maastricht. Pero el asedio de la ciudad tuvo lugar en 1579 y Espinel andaba entonces por Sevilla. Además, puede afirmar-

17. Buendía $(1986,22)$, analizando las semejanzas entre el héroe de Espinel y el cervantino, observó: «Don Quijote y Marcos intentan una nueva lectura del mundo, cuyo conjunto dará lo "quijotesco" como resultado: la gran diferencia estriba en que Cervantes hace que su personaje fracase continuamente, al menos en apariencia, mientras que Marcos es una especie de Quijote al que le salen las cosas bien, el cual consigue "desfacer" de verdad los entuertos que traían de cabeza al hidalgo manchego: las postrimerías del relato de Marcos constituyen una especie de "final feliz" en el que todos encuentran a su pareja, todos los sufrimientos quedan restañados, a veces abusando incluso de la anagnórisis y de increíbles historias de dobles personalidades, como la que hace posible el encuentro feliz del doctor Sagredo con su esposa Mergelina». 
se sin margen de error que, de haber participado en el asalto, se habría jactado de ello en las Relaciones sin omitir un solo detalle con el que vanagloriarse. Por el contrario, lo único que cuenta de la empresa es un lance peregrino:

Y fue que, en el saco de la ciudad, cogí el más lucido cuartago de todos
los que había en una casa principal, y subiendo sobre él en cerro, como en
tiempo de bulla no se mira mucho en las cosas, al tiempo que salía de la
ciudad, iban tras mí más de trecientos cuartagos, porque la que yo había
tomado era una yegua sazonada; y si no me arrojo de ella al suelo, me
dieran muchas manotadas los galanes que la seguían (Espinel 2021, 295).

Esta anécdota de la «yegua sazonada» rezuma un transparente aire ficticio y parece inspirada por el capítulo XV de la primera parte del Quijote, en el que unos yangüeses, defendiendo a sus yeguas, apalean a amo y escudero después de que «a Rocinante le vino en deseo de refocilarse con las señoras facas $[. .$.$] y se fue a comunicar su necesidad con ellas» (Cervantes 2015, I,$ 174). Habría sido esta una ocasión perfecta para referir hazañas, sin embargo, la estrecha identificación con su criatura no se lo permite, aunque encuentra lugar, en medio de ese marco soldadesco, para un entrenamiento que parece atenerse a la pauta cervantina. En este sentido, Rallo (2014, XX) apunta algo importante:

Es posible entender las referencias que se realizan en la novela sobre la intención de entrar en el ejército como otro deseo de Espinel de emulación de Cervantes, pero en este caso y a diferencia del episodio de Argel, ese deseo no se cumple ni en su ficticio doble, que es Marcos, al que no se deja ni entrar en batalla ni expresarse como militar, cuando sí lo hace como consejero, ensalmador, educador, cortesano, descubridor de patrañas.

También remite a Cervantes uno de los últimos episodios de la obra. En el descanso 18, irrumpen en el relato los bandoleros de la Sauceda, liderados por su caudillo Roque Amador. La condición y el nombre recuerdan de inmediato a Roque Guinart, el bandolero catalán que comparece en los últimos capítulos del segundo Quijote ${ }^{18}$. No parece fortuito que Espinel dé entrada a la figura de este bandido andaluz - que fue un personaje bastante popular, al igual que el catalán- justo en el mismo lugar en que lo hace Cervantes ${ }^{19}$. Ambos personajes resultan similares: elocuentes, amables, benevolentes y justos, como si su modus vivendi no consistiese en estafar,

18. Navarro $(2008, \mathrm{~L})$ ya advierte que «entramos en un espacio cervantino: los bandoleros andaluces con su jefe, Roque Amador, nos llevan a los catalanes del Quijote con Roque Guinart». Sobre el personaje de Roque Guinart, cfr. los trabajos de Weber (1986), Aladro (1992) y Roger (2016).

19. Fray Esteban Rallón, en su Historia de Xerez de la Frontera, describe los extravagantes métodos de estafa ideados por un caudillo de la Sauceda, Roque de Mesa, que son exactamente los mismos que Espinel describe en las Relaciones. Cfr. Rallón (1999, 180). Carrasco $(1972,27)$ cree que «Amador», como se llama el bandolero de las Relaciones, podría ser el apodo del famoso Roque de Mesa. Por su parte, Perot Roca Guinarda (o Rocaguinarda) fue asimismo un famoso e histórico bandolero catalán. 
robar y matar. Pero Espinel tomó algún elemento más del episodio cervantino. En el Quijote, entra en acción una hermosa joven vestida de hombre. Se trata de Claudia Jerónima, que confiesa haber tomado venganza de su amante Vicente Torrellas al enterarse de que había decidido casarse con otra. El lance tiene un trágico final, pues Torrellas asegura antes de morir que jamás faltó a su palabra de matrimonio y deja a la joven Claudia en un estado de desesperación. Por su parte, mientras el bandolero malagueño tiene confinados a Marcos y al doctor Sagredo en la cueva de la Sauceda, Espinel vuelve a traer a escena a doña Mergelina, también disfrazada -en hábito de paje-, que, tras escapar de los infieles que la habían retenido en Gibraltar, hace creer a todos que es un joven mozuelo. Si Roque Guinart se pone a los pies de la joven Claudia, fascinado por su hermosura y gentileza: «Roque, admirado de la gallardía, bizarría, buen talle y suceso de la hermosa Claudia, le dijo: -Ven, señora, y vamos a ver si es muerto tu enemigo, que después veremos lo que más te importare» (Cervantes 2015, I, 174); Espinel también subraya la impresión que la dama causa al bandolero andaluz, que no duda en ofrecer sus servicios a doña Mergelina: «El Roque Amador, con gran piedad de las lágrimas que al fin de su cuento derramó la bella mujer, la consoló y ofreció encaminarla con mucha seguridad y darle dineros para su viaje, preguntándole cómo se llamaba por que historia tan estraña no se quedase sin memoria» (Espinel 2021, 401).

Amador y Guinart se presentan cortados con la misma tijera: ambos son verdaderos hombres de acción que destacan por su indulgencia y liberalidad. No obstante, Cervantes y Espinel resuelven sendos episodios de un modo bien distinto. Como no podía ser de otra manera, el de Ronda reemplaza la violencia que envuelve la historia de los personajes cervantinos por un final feliz, y cierra las Relaciones con la anagnórisis del matrimonio Sagredo y la huida de Roque Amador. Pero, si en el Quijote Guinart tiene el papel de una figura verdaderamente heroica que nubla y empequeñece al caballero andante ${ }^{20}$, a Marcos poco le importa la condición valerosa de Amador, pues proceden de mundos moral y literariamente distintos. Espinel simplemente nos presenta a un personaje histórico muy popular de su tierra, sin atribuirle función específica alguna. Pero, dada la coincidencia de los nombres, la condición de bandoleros, el carácter y la imagen que se ofrece de ellos, la ubicación al final del relato o la irrupción de una hermosa mujer vestida de hombre invitan a pensar que Espinel, tras leer el Quijote de 1615, se decidió a incluir el episodio. Además, en el descanso 24 de la tercera relación, Marcos recuerda que fue Juan Sarmiento de Valladares quien consiguió acabar con los bandidos andaluces y el mismo Cervantes ya había puesto la noticia en boca de Berganza en el Coloquio de los perros:

... lo era entonces el licenciado Sarmiento de Valladares, famoso por la destruición de la Sauceda. Miraban a mi amo por las calles do pasaba, seña-

20. Cfr. Avalle-Arce (1976). 
lándole con el dedo como si dijeran: «Aquel es el valiente que se atrevió a reñir solo con la flor de los bravos de la Andalucía» (Cervantes 2001, 579).

Incluso la maravillosa relación del paso de Sagredo por tierras americanas, inserta al final de la novela y sin motivo aparente, pudo estar inspirada por la lectura reciente del Persiles y sus periplos bizantinos ${ }^{21}$.

\section{EL PERFIL DE LOS HÉROES}

Tanto Cervantes como Espinel ponen al frente de sus respectivas narraciones a dos hombres añosos y con condición de hidalgos. Que Cervantes se decantase por un cincuentón para interpretar el papel de un anacrónico caballero andante resultaba casi obligatorio dada la naturaleza cómica del libro, pero cuando Espinel optó por un viejo para representar a un pícaro estaba rompiendo con todos los esquemas que había trazado el nuevo género. Aunque el periplo vital de Obregón se inicia con su nacimiento en Ronda y parece alcanzar hasta los últimos años de la década de 1580, la voz del anciano maestro jamás desampara al escudero. En las Relaciones, los lectores son siempre aleccionados desde el punto de vista del Espinel anciano, que niega así cualquier suerte de independencia a su criatura. Este mecanismo narrativo le permitió a Espinel -y también a Cervantes- proyectar en el texto y en los protagonistas la experiencia vital y la visión del mundo de dos hombres cargados de años.

En ambos personajes, la pasión por la lectura aparece como un rasgo esencial. Ya sabemos que don Quijote ha enloquecido a causa de los libros, y Espinel quiso a su vez crear otro personaje aficionado a ellos, pero que sabe distinguir la ficción de lo real y que no está dispuesto a ceder el más mínimo protagonismo de las letras a las armas ${ }^{22}$. Y así, cuando empieza a servir al matrimonio Sagredo,

21. Cfr. Navarro (2008, LI) y Aguayo (2013, 375-76). Carrasco (1972, 49), en este sentido, advierte que «la inclusión de lo fabuloso en una obra tan vinculada a lo real e incluso a lo cotidiano como Marcos de Obregón es sin duda sorprendente [...]. Es posible también que la lectura del Persiles, que Espinel debió conocer cuando estaba concluyendo su obra, le indujese a dar cabida en ella a elementos maravillosos y a traer de nuevo al primer plano a Sagredo y Mergelina, dándoles ahora talla heroica y categoría de dechado». La relación fantástica del doctor, a quien Marcos pasa la batuta como narrador, abarca cuatro descansos, del 19 al 23. Este relato, con aroma de ficción bizantina, parece coincidir en parte con lo acaecido a la desafortunada expedición de la flota de Flores de Valdés hacia el Nuevo Mundo, como ha demostrado Valentín de Pedro (1954) en su imprescindible trabajo sobre las fuentes de este episodio. Sobre el uso de lo maravilloso en el Marcos de Obregón, cfr. los trabajos de Rallo (2006; 2010).

22. Recordemos las significativas palabras de Marcos cuando se despide de su padre para marcharse a la universidad: «Y con esto me echó la bendición y me dio lo que pudo, y una espada de Bilbao, que pesaba más que yo, que en todo el camino no me sirvió sino de estorbo» (Espinel 2021, 92). Para Rallo $(2014,74)$, «la espada es un símbolo y funciona como leitmotiv a lo largo de toda la narración. En esta primera referencia significa un estorbo, tanto porque Marcos inicia una vida en la que las espadas ya no tienen valor, pues pertenecen al mundo caballeresco, remitiendo al Alonso Quijano que en su locura rescata sus armas del orín y del moho, como porque Marcos va a oponer la resolución de los problemas y de los obstáculos con la prudencia y la paciencia, con virtudes morales, 
el doctor le muestra una estantería repleta de armas y pregunta: «¿Qué os parece de mi recámara? Miradla bien, que en Alcalá era temida aquella espada». La respuesta no deja margen a la duda: «No miraba - dije yo- sino adónde estaban los libros, que soy aficionado a ellos» (Espinel 2021, 30). El de Ronda insiste en distanciar a su criatura de la violencia que representa el caballero andante y subraya los beneficios que la lectura aporta a su escudero:

Fuime a mi posadilla, que, aunque pequeña, me hallé con una docena de amigos que me restituyeron mi libertad; que los libros hacen libre a quien los quiere bien. Con ellos me consolé de la prisión que se me aparejaba, y satisfice la hambre con un pedazo de pan conservado en una servilleta, y a la dieta, con un capítulo que encontré en alabanza del ayuno. ¡Oh, libros, fieles consejeros, amigos sin adulación, despertadores del entendimiento, maestros del alma, gobernadores del cuerpo, guiones para bien vivir, y centinelas para bien morir! ¿Cuántos hombres de obscuro suelo habéis levantado a las cumbres más altas del mundo? ¿Y cuántos habéis subido hasta las sillas del cielo? ¡Oh, libros, consuelo de mi alma, alivio de mis trabajos, en vuestra santa doctrina me encomiendo! (Espinel 2021, 85).

Marcos, similar a don Quijote en edad, condición social, afición a la lectura y concepción del mundo, termina convirtiéndose en una contrafigura del caballero, que desbarata el verdadero valor de la lectura. A Marcos los libros le empujan a ser pacífico, razonable y reflexivo. Nada que ver con los vehementes arrebatos de don Quijote.

La estrategia que Espinel sigue respecto al modelo picaresco y, en especial, respecto al Guzmán de Alfarache es la de adaptar los mecanismos del género a sus propios intereses hasta dotarlos de una nueva naturaleza narrativa. En ningún caso alcanza, sin embargo, la libertad de la que Cervantes se dotó a sí mismo como narrador respecto a cualquiera de los modelos a los que podía haber acudido. A pesar de su singularidad, el Marcos de Obregón sigue siendo un texto picaresco, por más que el maestro de Ronda se impusiera el objetivo de crear un producto singular y diferente. No cabe la menor duda de que tuvo muy a la vista la tarea llevada a cabo por Cervantes en sus dos Quijotes en el marco genérico de los libros de entretenimiento ${ }^{23}$. Para empezar, partió de un género que Cervantes quiso esquivar expresamente, por lo que le quedaba campo abierto. Presentó luego un personaje concebido a su imagen y semejanza que le permitía, rizando el rizo del recurso autobiográfico, dar forma ficticia a su propio personaje. Y para que no cupiera duda alguna a los lectores, se aseguró de que todos entendieran a las claras que ese ejemplo de nobleza, virtud y paciencia no era otro que el propio Vicente

a la trasnochada de la fuerza física que la espada pesada representa. Marcos nunca la usa y la perderá junto con la capa y el sombrero, en el lance de la esclusa a la que le arrojaron los bilbaínos por pretender a una dama. Marcos sabe de la inutilidad de las viejas armas para una vida actual, de lo que don Quijote es un buen ejemplo»».

23. Carrasco $(1990,129)$ ya señaló que «en muy fundamentales aspectos de la narrativa de Vicente Espinel, el modelo picaresco se ve modificado por la fuerza del ejemplo de Cervantes». 
Espinel bajo la máscara de un escudero llamado Marcos de Obregón ${ }^{24}$. Con la publicación de las Relaciones, además, Espinel invalidaba las palabras del caballero andante cuando se decía entre sí que «nunca hazañas de escuderos se escribieron» (Cervantes 2015, I, 704). Sin embargo, Cervantes y su Quijote están siempre presentes como referencia y Marcos viene a convertirse en contrapunto y alternativa al hidalgo cervantino.

Otro elemento en que converge la configuración de ambos personajes es la posible existencia de otro yo. Se introduce este lugar común, en el caso de Cervantes, de la mano del caballero del Bosque, que presume de su victoria sobre don Quijote de la Mancha y el propio don Quijote le responde:

Habéis de saber que ese don Quijote que decís es el mayor amigo que en este mundo tengo, y tanto, que podré decir que le tengo en lugar de mi misma persona, y que por las señas que dél me habéis dado, tan puntuales y ciertas, no puedo pensar sino que sea el mismo que habéis vencido (Cervantes $2015, \mathrm{I}, 803$ ).

También Espinel hace que Marcos haga camino con el licenciado Hernando de Villaseñor, oidor de Sevilla ${ }^{25}$, al que le han llegado noticias del escudero:

-Cierto que me dijeron ayer que buscaba cabalgadura para venir este camino Marcos de Obregón, hombre de buen gusto y partes, a quien yo deseo conocer.

-Así es -dije yo-, yo le vi buscar en qué venir.

-¿Conócelo vuesa merced? -preguntó el oidor don Hernando de Villaseñor.

Yo respondí:

-Sí, señor, y es grande amigo mío (Espinel 2021, 348).

Y continúa más adelante:

Y tornando a mis alabanzas, sin conocerme, dijo que deseaba mucho conocer a Marcos de Obregón: lo uno por las grandes nuevas que tenía de su ingenio, y lo otro porque eran vecinos en los pueblos, porque él era de

24. La primera persona predomina en el grueso de las Relaciones, sin embargo, en varias ocasiones Espinel cambia a tercera persona, apelando al «autor de este libro», para dejar constancia de que lo que está contando se nutre de vivencias propias. Este desdoblamiento gramatical aparece sobre todo cuando narra hechos de los que se siente particularmente orgulloso, como, por ejemplo, cuando le encomiendan realizar las composiciones en latín y en castellano para las honras fúnebres de la reina Ana de Austria: «Llegué a tiempo que se celebraban las obsequias de la santísima reina doña Ana de Austria. Y habiendo buscado a quien cometer la traza, historias y versos de la vida ejemplar de tan gran señora, pudiendo cometellas a muy grandes ingenios, tuvo por bien el Magistrado de Milán de cometellas al autor de este libro» (Espinel 2021, 290). Vemos, pues, que la acción la empieza Marcos en primera persona, «Llegué a tiempo» y la termina «el autor de este libro» en tercera. Se trata de un desdoblamiento autor/Marcos que, en estos casos, se reconoce fácilmente porque está gramaticalmente marcado.

25. Hernando de Villaseñor fue consejero de Indias entre 1618 y 1636 y presidente de la Casa de Contratación de 1621 a 1625 (Schäfer 1935, 344). 
Cañete la Real, y Obregón natural de Ronda. Y preguntome qué traza de hombre tenía y qué trato y qué proceder. Y le respondí:

-La proporción y traza de su persona es de la misma manera que la mía, y el trato y proceder del mismo que el mío; que, como somos tan grandes amigos, yo le sigo a él, y él a mí (Espinel 2021, 351).

Haley $(1994,107)$ ya señaló que esta estratagema que emplea Marcos
representa, de manera microscópica, la visión que Espinel - quien casi con toda seguridad recordaba cómo utilizó Cervantes el recurso del engaño con la verdad - tuvo de la novela entera. Paralelamente a como Marcos juega con el oidor, está jugando Espinel con el lector, a quien, mientras tanto, ofrece las suficientes pistas para mantener vivo su interés hasta el final de la obra.

Nos encontramos - continúa Haley- «ante un desdoblamiento dentro del desdoblamiento básico de la novela». Pero si el impetuoso caballero andante revela casi al instante su identidad al del Bosque, Marcos se regodea con los elogios que le dispensa el licenciado Villaseñor y, solo cuando se apartan y está a cierta distancia, se identifica a gritos:

-Señor oidor, iyo soy Marcos de Obregón!

Y picando con toda la priesa posible, cogí el camino de Málaga o de Gibraltar, que a uno de estos lugares era mi viaje (Espinel 2021, 361).

El eco cervantino parece claro, aunque, en este caso, ya contaban con el antecedente de Mateo Alemán, que había hecho que Sayavedra, volviéndose loco, adoptase la identidad y el nombre de Guzmán de Alfarache, mientras vociferaba: «iYo soy la sombra de Guzmán de Alfarache! ¡Su sombra soy, que voy por el mundo!» (Alemán 2012, 582).

Buendía $(1986,21)$ se detuvo a analizar ese desdoble en las figuras de ambos personajes:

\begin{abstract}
Don Quijote y Marcos desarrollan su capacidad volitiva, ese extraordinario esfuerzo por "querer ser" frente a las presiones exteriores, desdoblándose magistralmente en un doble plano: lo que de verdad son y lo que pretenden ser, y este último estadio les lleva a ser objeto de burlas, sobradamente conocidas en el hidalgo manchego, y de gran interés en Marcos de Obregón, pues constituyen la trama de toda novela picaresca, género en el cual dar burlas y recibirlas resulta casi obligatorio.
\end{abstract}

Es lo que sucede cuando, con veinte años, Marcos sale de Ronda y se detiene a descansar en el mesón del Potro. Pretende allí ser el célebre Vicente Espinel que está escribiendo la novela, cayendo sin embargo en el engaño de un bellaco que lo convence de que todos lo conocen por gran poeta, latino y músico, pese a que el maestro de Ronda por esos años era un personaje desconocido. Y es que Espinel se desdobla continuamente, anulando así cual- 
quier margen de actuación a su criatura y convirtiendo a Marcos, por ende, en un personaje que no acaba de construirse por completo.

No obstante, aunque en ocasiones las sendas de Marcos y Espinel se bifurquen, la novela narra la gradual fusión entre ambos, autor y criatura, que acaban escribiendo juntos el final feliz de las Relaciones en la capilla del obispo de Plasencia, identificados por completo. Nada que ver con Alonso Quijano y don Quijote, que se excluyen entre sí, pues no cabe convergencia entre dos existencias tan diversas. Tras la muerte figurada del caballero andante en la playa de Barcelona, a Cervantes ya no le interesa relatar la insustancial vida de Alonso Quijano y ya solo le acompaña, a medida que el caballero se va extinguiendo, hasta su lecho de muerte.

\section{ESTRATEGIAS PARA LA FICCIÓN}

Hay un último elemento más que conecta el Marcos de Obregón con el Quijote. Se trata de las técnicas narrativas, que tanta importancia terminan adquiriendo en la historia cervantina. El Quijote no es solo la aventura del caballero y su escudero, sino también la peripecia de cómo se narra esa historia. Como ha escrito Gómez Canseco $(2005,58)$, la intriga

está poblada de personajes cuya labor es la de escribir, recopilar, traducir, glosar y trasmitir al lector los ires y venires de don Quijote. Entre todos ellos forman otra maravillosa andanza, en la que los caminos y las ventas han sido sustituidos por legajos, manuscritos, anales y cartapacios.

Tras la lectura del Quijote, Espinel pudo experimentar con nuevos modos de contar una historia y, de hecho, llegó a introducir novedades inusitadas hasta el momento, pese a que no acabara de rematarlas ${ }^{26}$.

Espinel rompe desde el principio con la pauta picaresca-que dispone la obra de manera lineal y $a b$ ovo- al iniciar la narración in medias res ${ }^{27}$. A partir de ese mismo instante, se introduce la primera analepsis de la obra, que nos retrotrae a unos años atrás y, algo más adelante, otra segunda que nos lleva a la infancia de Marcos en su Ronda natal. Resulta llamativo que Espinel cambie entonces el plano discursivo de un relato que hasta ese momento

26. Cfr. Aguilera (1996).

27. Moratilla $(1998,104)$ señala al respecto: «Esta disposición narrativa nada tiene que ver con la de los relatos picarescos. En todos ellos un futuro nuevo se abre para sus protagonistas cuando se deciden a contar su vida pasada. Marcos solo adivina, anciano y enfermo, la proximidad de la muerte que no ofrece ya expectativas de vida. Las relaciones de interdependencia que notábamos en la secuencia lineal del Lazarillo y del Guzmán no tienen en este caso sentido, porque lo original aquí ha sido la ruptura del orden cronológico natural, la fragmentación del tiempo y el espacio, artificiosamente recompuestos en ingeniosos desplazamientos de dirección circular. No es difícil percibir en estos desplazamientos la presencia de una nueva sensibilidad creativa, la manierista, una de cuyas características, la principal para A. Hauser, estriba en la desintegración de la unidad espacial». 
iba dirigido al cardenal Sandoval ${ }^{28}$, y opte repentinamente por un nuevo interlocutor, el ermitaño a quien le cuenta su vida. Pasa así a un modelo dialogístico, aunque, a decir verdad, el ermitaño apenas interviene y el lector casi se olvida de su presencia.

Esos saltos en el tiempo resultan muy frecuentes. Veamos algunos ejemplos:

Púseme a la puerta del mesón para ver si pasaba el macho o persona que de él me diese nuevas. [...] adonde algunos años después pasó en presencia mía una desgracia muy digna de contarse para que se vea cuánta obligación tienen los hijos de seguir el consejo de los padres, aunque les parezca que repugna a su opinión (Espinel 2021, 139).

Marcos relata el caso del joven que murió ahogado por desoír las advertencias de su padre, $y$, finalmente, admite:

Pasó este caso en este mismo lugar y en presencia del marqués don Luis de Haro y de su hijo, el marqués don Diego López de Haro; que, cuando esto se escribe, están vivos y más mozos que el autor, en cuya compañía se halló presente a este infelice suceso (Espinel 2021, 140).

El salto temporal es aquí hacia delante, pero Marcos, que empieza la acción en primera persona, asegurando que el suceso «pasó en presencia mía», se contradice al final al confesar que fue el «autor» quien presenció ese truculento espectáculo en compañía de los marqueses de Haro.

Junto a las dos analepsis principales, a lo largo de las Relaciones encontramos numerosos saltos atrás en el tiempo, como el siguiente: «Y pues se ha ofrecido materia tan excelente y divina virtud como es el agradecimiento, en tanto que llegamos a Adamuz, tengo de referir un caso digno de saberse, que le pasó al autor de este libro viniendo de Salamanca...» (Espinel 2021, 130). No obstante, la mayor incongruencia temporal de la novela la localizamos en la parte argelina, cuando Marcos conversa con el renegado en las fiestas en honor al profeta Alí. El escudero está haciendo apología de nuestras fiestas taurinas cuando el ermitaño interrumpe el relato en estos términos:

Díjome aquí el ermitaño:

-¿Pues cómo no hace vuesa merced mención de la que hizo en Valladolid don Felipe el Amado en el nacimiento del príncipe nuestro señor?

Respondí yo:

28. Marcos interrumpe la relación de su vida para disculparse ante don Bernardo, dedicatario de las Relaciones, por haberse extendido demasiado explicando algunas minucias acaecidas durante su estancia con el matrimonio Sagredo: «Perdóneme, vuesa señoría ilustrísima, si le canso con estas niñerías que me pasaron con este médico, que las digo porque quizá encontrará con ellas alguno a quien aprovechen» (Espinel 2021, 50). Como ha apuntado Rey Hazas $(2009,211)$ no hay «ninguna razón estructural para que una referencia al destinatario interrumpa el relato», por lo que nos encontramos ante «una imitación explícita y evidente al Lazarillo [...], como si la Vida del escudero fuese una carta autobiográfica, y lo hace así porque el Lazarillo es en este caso su modelo indudable». 
-Porque no había de contar yo en profecía lo que aún no había pasado... (Espinel 2021, 255).

Hablan de las famosas fiestas de cañas y toros que se celebraron en 1605 con motivo del nacimiento de Felipe IV, pese a que el periodo vital que abarca la novela va desde 1550 hasta unos cuarenta años después. Aun cuando se esfuerce en respetar la cronología interna del relato y concertar el tiempo de los sucesos reales con el de la narración, es evidente que el anciano maestro se confunde, su presente lo domina todo, porque esas fiestas vallisoletanas no se solemnizaron hasta al menos una década después de la conversación en la ermita. Quiere esto decir que tanto Marcos como su interlocutor -sin advertirlo Espinel- hablaban profetizando.

Otro tanto sucede con los juegos -tan hondamente cervantinos- entre historia y ficción, que en el Marcos de Obregón tienen un importantísimo protagonismo. No hay que olvidar que una buena parte de su ficción se construye con materiales históricos y continuas referencias a la España contemporánea. Espinel alude aquí y allá a acontecimientos señalados y otorga un papel destacado a infinidad de personalidades de su época que comparecen en la obra con el estatuto de personajes. A ello se añade un proceso de autorrevelación que avanza y se hace cada vez más complejo en el relato. Piénsese simplemente en el momento en que le encargan unas composiciones durante su estancia en Italia para las honras fúnebres de la reina Ana de Austria o cuando los músicos en el barco cantan sus versos a la guitarra. El lector precisa de referencias extraliterarias para entender el juego en toda su sofisticada dimensión. No otra cosa había hecho Cervantes en el Quijote, otorgando a la realidad una dimensión sorprendentemente ficticia.

Espinel aprovechó esos ensayos para introducir elementos que giran en torno al proceso de creación literaria. Es ahí, en ese continuo ir y venir de la primera a la tercera persona, cuando tomamos conciencia de la presencia de alguien que escribe la historia y de que, así como el «autor» conoce al detalle la vida de Marcos, el escudero también sabe cosas de ese «autor» que no desaprovecha ocasión para darse protagonismo en la historia. Pero, al cabo, todos esos juegos se le terminan por escapar de las manos. Espinel no llega a controlar por completo los hilos de su historia. Tampoco lo hizo Cervantes. Al fin y al cabo, ambos avanzaban por territorios nuevos para la ficción y no sabían con seguridad hacia dónde se dirigían.

En ese camino hacia la invención de nuevos modos de narrar, Cervantes, como no podía ser menos, ocupa un señaladísimo lugar. Aunque a distancia, el Marcos de Obregón también ha de considerarse un hito singular en ese proceso. Basta ver cómo juega Espinel con el lector, cómo, ante sus mismos ojos, se pone y se quita su máscara de escudero, introduce cambios en la disposición de la trama, se divierte experimentando con distintas voces, entreteje historias en la historia que le cuenta al ermitaño, cambia de interlocutores o cuenta lo que contó y lo que le contaron a él, siempre esforzándose en atar los cabos de su historia, aunque fracase. 


\section{UN PÍCARO A LA SOMBRA DE CERVANTES}

Allá por 1800, Pellicer apuntó en su Vida de Cervantes a un vínculo entre el alcalaíno y Vicente Espinel. El cotejo de los textos de ambos autores corrobora que no andaba mal encaminado. Para empezar, esos textos invitan a pensar que la supuesta amistad entre los dos escritores no fue tal; al menos en lo que al rondeño corresponde, por más que literariamente admirara a su contrincante. Fruto de esa fascinación unida al desapego es el visible ejercicio de emulación que desplegó en su obra. El Marcos de Obregón, por más que se ajustara a un patrón picaresco, con quien verdaderamente aspiraba a competir era con el mismísimo Quijote. Por eso Espinel configuró a su personaje como respuesta al caballero cervantino, convirtiéndolo en su contrafigura y haciendo que los conflictos que el de la Mancha afronta por la fuerza Marcos los resuelva por vía de la paz y la palabra. Al tiempo que buscó ocasiones para lanzar sutiles y encubiertos dardos contra Cervantes, como hizo con la búsqueda del macho o con la crítica a los libros de «burlas y cuentos entremesiles», no dudó en acudir a su rival como fuente e insertar en su obra episodios que beben de la ajena. Siguiendo la estela cervantina, incluso se otorgó a sí mismo la libertad de jugar con el tiempo y la articulación del relato, buscando aquí un camino propio.

Para afrontar la tarea, Espinel eligió un género, como la picaresca, al que Cervantes había renunciado de antemano ${ }^{29}$. Bien es verdad que Rinconete $y$ Cortadillo, el Coloquio de los perros o, en cauce de comedia, El rufián dichoso muestran un claro interés por el asunto de los pícaros, aunque no por el género como estructura narrativa, sobre el que se permitió hacer un chascarrillo con el personaje de Ginés de Pasamonte ${ }^{30}$. Espinel, por su parte, trabajó ateniéndose al marco narrativo que le ofrecía la invención del Lazarillo y del Guzmán; pero, al tiempo, mantuvo la mira puesta en el Quijote. Ese complejo equilibrio, que afectó fundamentalmente a la construcción narrativa y a la caracterización del personaje, resulta decisivo para explicar la extraña naturaleza del Marcos de Obregón y el difícil encaje que tiene en el corpus de la picaresca ${ }^{31}$. Fascinado por la genialidad de la obra cervantina,

29. Sobre la relación del Marcos de Obregón con el género picaresco, cfr. los trabajos de Calabritto (1929), Lara y Rallo (1979), Linares (1987), Moratilla (1998), Paredes (2000), Peña (2003), Aranda (2010) y Rallo (2014, XXI-XXXI).

30. Sobre Cervantes y el género picaresco, cfr., por ejemplo, Castro (1926), Blanco Aguinaga (1957), Alfaro (1971), Bataillon (1973), Dunn (1982), Rey (1996), Muñoz (2013), Núñez (2014) y Rodríguez Álamo $(2015,2016)$.

31. Lara y Garrote (1993, II, 619-682) recogen las contribuciones más relevantes de la crítica acerca de la problemática posición del Marcos en el corpus picaresco. Zamora Vicente (1993, II, 863) ha defendido que el Marcos de Obregón no se trata de una novela picaresca, sino de un «libro de memorias». Según Rico (1970, 120), «ni por el protagonista ni por la estructura es una novela picaresca»; Valbuena Prat $(1943,921)$, por su parte, lo define como «libro de viajes empotrado en picaresca» y para Gili Gaya $(1940,19)$ sí es una novela picaresca, pero señala que «lo picaresco tiene en ella un valor meramente episódico, no es el núcleo de la obra». Carrasco $(1972,630)$ señala algo importante que tiene que ver con la recepción del Marcos, y es que «aunque la posición de Espinel sea de reacción frente al principal supuesto del género picaresco, cuya enseñanza deriva de la conducta errada del protagonista, ni por la coyuntura histórica, ni por la materia y estructura misma de la obra puede desgajar- 
Espinel probablemente se propuso hacerse un hueco en el parnaso de la narrativa transformando el género de pícaros, precisamente el mismo que había sido esquivado por Cervantes. Su principal instrumento para llevar a cabo tal empresa fue un personaje completamente opuesto al pícaro común, un escudero pasado por el tamiz de la escritura cervantina.

\section{BIBLIOGRAFÍA CITADA}

Aguayo Cisternas, Gonzalo Ricardo. 2013. La materia novelesca de las "Relaciones de la vida del escudero Marcos de Obregón" de Vicente Espinel. Barcelona: Universitat.

Aguilera Serrano, Manuel. 1996. Géneros, sujeto narrativo y estructura cronotópica del "Marcos de Obregón". Málaga: Universidad.

Aladro Font, Jorge. 1992. «Entre Roque Guinart y Don Quijote, o el desdoblamiento de Cervantes». Anales Cervantinos 30: 129-137. https://doi.org/10.3989/anacervantinos. 1992

Alemán, Mateo. 2012. Guzmán de Alfarache, ed. Luis Gómez Canseco. Madrid: Real Academia Española.

Alfaro, Gustavo A. 1971. «Cervantes y la novela picaresca». Anales Cervantinos 10: 23-31.

Aranda, María. 2010. «Vicente Espinel y el modelo picaresco: la Vida del escudero Marcos de Obregón o las ambigüedades de una figura ejemplar». Criticón 110: 57-65.

Avalle-Arce, Juan Bautista de. 1976. Don Quijote como forma de vida. Valencia: Fundación Juan March-Castalia.

Bataillon, Marcel. 1973. «Relaciones literarias». En Suma cervantina, ed. J.B. AvalleArce, 215-232. Londres: Tamesis.

Blanco Aguinaga, Carlos. 1957. «Cervantes y la picaresca. Notas sobre dos tipos de realismo». Nueva Revista de Filología Hispánica XI: 322-323.

Buendía López, José Luis. 1986. «El pícaro andaluz: los ideales humanistas del escudero Marcos de Obregón». En Conferencias de los cursos de verano de la Universidad de Córdoba sobre "El barroco en Andalucía", coord. Manuel Peláez del Rosal, IV, 17-26. Córdoba: Universidad, 4 vols.

Calabritto, Giovanni. 1929. I Romanzi Picareschi di Mateo Alemán e Vicente Espinel. La Valeta: Tipografía del Malta.

Carrasco Urgoiti, M. ${ }^{a}$ Soledad, ed. 1972. Vicente Espinel. Relaciones de la vida del escudero Marcos de Obregón. Madrid: Castalia, 2 vols.

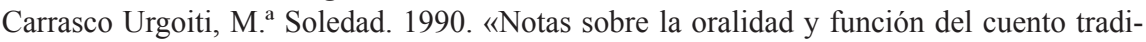
cional en Vicente Espinel». Bulletin Hispanique 92 (1): 125-140.

Castro, Américo. 1926. «Lo picaresco y Cervantes». Revista de Occidente 33: 349-361.

Cervantes, Miguel de. 2001. Novelas ejemplares, ed. Jorge García López. Barcelona: Crítica.

Cervantes, Miguel de. 2014. La Galatea, eds. Juan Montero et al. Madrid: Real Academia Española.

se totalmente Marcos de Obregón del conjunto novelístico que promueve la obra de Alemán, y de hecho hará un papel crucial en la propagación del género a otras literaturas». A nuestro juicio, hablar de las Relaciones es hablar de picaresca. En este sentido, nos parece muy acertada la interpretación que hace de la obra Lázaro Carreter: según el crítico, aunque Espinel rechaza la materia, sí «transfiere la truhanería al mundo que le rodea», y acepta la forma al relatar «su vida conforme a esquemas picarescos». Este procedimiento que emplea Espinel es decisivo, pues, «sin la picaresca actuando como plano de referencia, el fino escritor rondeño no habría compuesto el Obregón» (Lázaro Carreter 1978, 200). Sobre la recepción de la obra de Espinel, cfr. Lara y Garrote (1993, I, 41-74). 
Cervantes, Miguel de. 2015. Don Quijote de la Mancha, ed. Francisco Rico. Madrid: Real Academia Española, 2 vols.

Cervantes, Miguel de. 2016. Viaje del Parnaso. En Viaje del Parnaso y poesías sueltas, eds. José Montero Reguera y Fernando Romo Feito, 3-143. Madrid: Real Academia Española.

De Pedro, Valentín. 1954. «La geografía fantástica de V. Espinel. El mito de los gigantes patagónicos en la Vida del escudero Marcos de Obregón». En América en las letras españolas del Siglo de Oro, 112-132. Buenos Aires: Editorial Sudamericana.

Dunn, Peter N. 1982. «Cervantes De/Re-Constructs the Picaresque». Cervantes: Bulletin of the Cervantes Society of America 2(2): 109-132.

Espinel, Vicente. 2001. Diversas rimas. En Obras completas (II), ed. Gaspar Garrote. Málaga: Clásicos malagueños, 2 vols.

Espinel, Vicente. 2021. Relaciones de la vida del escudero Marcos de Obregón, ed. Natalia Palomino Tizado. Madrid: Sial/Prosa Barroca.

Gili Gaya, Samuel. 1940. «Prólogo». En Vicente Espinel. Vida de Marcos de Obregón, 7-23. Madrid: Espasa-Calpe, 2 vols.

Gómez Canseco, Luis. 2005. El Quijote, de Miguel de Cervantes. Madrid: Síntesis.

Gracia, Jordi. 2016. Miguel de Cervantes. La conquista de la ironía. Madrid: Taurus.

Haley, George. 1994. Vicente Espinel y Marcos de Obregón: biografía, autobiografía y novela. En Vicente Espinel. Obras Completas, coord. José Lara Garrido, I, 7-283. Málaga: CEDMA, 2 vols.

Heathcote, Anthony. 1989. «Selecta malacitana: vida y época (de Vicente Espinel)». Jábega 63: 70-80.

Lara Garrido, José. 1993. «La Sátira a las damas de Sevilla de Vicente Espinel: edición crítica y comentario literal». En Vicente Espinel. Historia y Antología de la crítica, eds. José Lara y Gaspar Garrote, II, 411-446. Málaga: CEDMA, 2 vols.

Lara Garrido, José y Gaspar Garrote Bernal, eds. 1993. Vicente Espinel. Historia y antología de la crítica. Málaga: CEDMA, 2 vols.

Lara Garrido, José y Asunción Rallo Gruss. 1979. «Poética narrativa y discurso picaresco en la Vida del escudero Marcos de Obregón». En Estudios sobre Vicente Espinel. Anejos de Analecta Malacitana, 103-129. Málaga: Universidad.

Lázaro Carreter, Fernando. 1978. Lazarillo de Tormes en la picaresca. Barcelona: Ariel.

Linares Alés, Francisco. 1987. La "Vida del escudero Marcos de Obregón” y su relación con el género novela picaresca (estudio semiótico). Granada: Universidad.

Moratilla García, Emilio. 1998. «La Vida del escudero Marcos de Obregón y su problemática inserción en la novela picaresca». En Convengo di Studi Ispanici in memoria di Mario Damonte, 95-112. Génova: Accademia Ligure di Scienza e Lettere.

Muñoz Sánchez, Juan Ramón. 2013. «La novela de Cervantes y las primeras novelas picarescas». Revista de Filología Española 93(1): 13-132. https://doi.org/10.3989/ rfe.2013.04

Navarro Durán, Rosa. 2008. «Introducción». En Novela picaresca IV, XI-LV. Madrid: Fundación José Antonio de Castro.

Núñez Rivera, Valentín. 2014. «Metamorfosis cervantinas de la picaresca. Novela y teatro». En Guanajuato en la geografía del Quijote. XXIV Coloquio Cervantino Internacional, 95-136. Guanajuato (México): Fundación Cervantina de México/ Museo Iconográfico del Quijote.

Paredes Núñez, Juan Salvador. 2000. «Contar en la picaresca: en torno a la estructura del Marcos de Obregón». Hispanic Research Journal: Iberian and Latin American Studies 1(2): 129-138. 
Pellicer, Juan Antonio. 1800. Vida de Miguel de Cervantes Saavedra. Madrid: Gabriel de Sancha.

Peña, Beatriz Carolina. 2003. «El ensalmador falso y los hidalgos burlados: la picaresca en la Vida del escudero Marcos de Obregón, de Vicente Espinel». Bulletin of Spanish Studies: Hispanic Studies and Research on Spain, Portugal and Latin America 80: 401-419.

Pérez de Guzmán, Juan. 1881. «Vicente Espinel y su obra». En Vicente Espinel. Vida del escudero Marcos de Obregón, I-XXXII. Barcelona: Biblioteca «Arte y Letras».

Rallo Gruss, Asunción. 2006. «La narración verosímil de lo maravilloso en la Vida del escudero Marcos de Obregón de Vicente Espinel». Lectura y Signo, Revista de Literatura 1: 125-164.

Rallo Gruss, Asunción. 2010. «La ficción como novella: Boccaccio en la Vida del escudero Marcos de Obregón». Cuadernos de Filología Italiana Extraordinario: 67-79.

Rallo Gruss, Asunción, ed. 2014. Vicente Espinel. Relaciones de la vida del escudero Marcos de Obregón. Sevilla: Fundación José Manuel Lara.

Rallón, Fray Esteban. 1999. Historia de Xerez de la Frontera y de los reyes que la dominaron desde su primera fundación (III), eds. Ángel Marín y Emilio Martín. Cádiz: Universidad - Ayuntamiento de Jerez de la Frontera, 4 vols.

Rey Hazas, Antonio. 1996. «El Quijote y la picaresca: la figura del hidalgo en el nacimiento de la novela moderna». Edad de Oro XV: 141-160.

Rey Hazas, Antonio. 2009. "Vicente Espinel y el Lazarillo de Tormes: el escudero en la novela picaresca». En Congreso Internacional Andalucía Barroca: actas III, (Literatura, música y fiesta), coord. Alfredo J. Morales, 207-220. Sevilla: Junta de Andalucía - Consejería de Cultura.

Rico, Francisco. 1970. La novela picaresca y el punto de vista. Barcelona: Seix Barral.

Rodríguez Álamo, Francisco de Borja. 2015. Cervantes y la picaresca. Madrid: Universidad Autónoma.

Rodríguez Álamo, Francisco de Borja. 2016. «La picaresca cervantina: narrador y diálogo». Anuario de estudios cervantinos 12: 311-324.

Roger, Isabel M. 2016. «Don Quijote y Roque Guinart frente a los poderosos». Anales Cervantinos 48: 183-201. https://doi.org/10.3989/anacervantinos.2016

Schäfer, Ernst. 1935. El Consejo Real y Supremo de las Indias: historia y organización del Consejo y de la Casa de Contratación (I). Sevilla: Escuela de estudios hispanoamericanos, 2 vols.

Sevilla, Florencio. 2001. «Presentación». En La novela picaresca española, V-LIII. Madrid: Castalia.

Suárez Figaredo, Enrique. 2004. Cervantes, Figueroa y el crimen de Avellaneda. Barcelona: Ediciones Carena.

Valbuena Prat, Ángel. 1943. «Vicente Espinel y la Vida de Marcos de Obregón. Prólogo explicativo». En La novela picaresca, 921-922. Madrid: Aguilar.

Weber, Alison. 1986. «Don Quijote with Roque Guinart». Cervantes: Bulletin of the Cervantes Society of America 6(2): 123-140.

Zamora Vicente, Alonso. 1993. «Tradición y originalidad en El escudero Marcos de Obregón». En Vicente Espinel. Historia y antología de la crítica, eds. José Lara Garrido y Gaspar Garrote, II, 863-890. Málaga: CEDMA, 2 vols.

Recibido: 25 de mayo de 2020

Aceptado: 31 de agosto de 2020 